\title{
Optimum Size and Shape of Quadrat for Sampling Herbage Weight in Grasslands of Northern Greece
}

\section{VASILIOS P. PAPANASTASIS}

Highlight: Five quadrat sizes, $0.0625,0.125,0.250,0.500$, and 1 square meter and three shapes, square, rectangular, and circular were tested in an ungrazed foothill bunchgrass range of northern Greece to determine the optimum quadrat for sampling herbage yield. Data on total herbage weight and clipping time were collected, which showed a high degree of variability. Shapes did not produce significantly different results. Larger quadrats were more efficient statistically but less efficient timewise than smaller quadrats. By maximizing the product of statistical and time efficiency, it was found that a quadrat of $0.0625 \mathrm{~m}^{2}$ of any shape was the optimum quadrat for herbage weight estimates.

The subject of size and shape of quadrat for herbage weight estimates has been studied by several investigators working both on range and nonrange vegetation and several reviews are available (Brown 1954; Joint Committee 1962; Greig-Smith 1964; Morris 1967; Kershaw 1973). No uniform size was found to be applicable to all vegetation types; on the contrary, the most suitable size of quadrat depends on the distribution of vegetation and a special size was suggested almost for every particular type (Milner and Hughes 1968).

More conclusive is the information about the right shape of quadrat. Although square plots have been used commonly almost by tradition, considerable recent evidence has revealed that rectangular quadrats are most appropriate for maximum accuracy and they are suggested for range vegetation (Joint Committee 1962). However, Van Dyne et al. (1963) have found that circular plots were more suitable on a bunchgrass range than square or rectangular quadrats.

Optimum quadrat size and shape takes into account not only the accuracy of the estimate but also the time required for sampling, which is the cost of sampling. Despite the importance of the cost in field studies, relatively few investigators have considered this factor in their studies (Pechanec and Stewart 1940; Wiegert 1962; Van Dyne et al. 1963).

This research was designed to determine the optimum quadrat size and shape for sampling herbage weight in a foothill bunchgrass range of northern Greece. Such a quadrat will be of considerable value for any detailed study of herbage production undertaken in those grasslands.

The author is range scientist, North Greece Forest Research Center, Vassilika, Thessaloniki, Greece.

Manuscript received March 11, 1977.

\section{Study Site}

The experiment was carried out in an area located $25 \mathrm{~km}$ east of the city of Thessaloniki, fenced against grazing for almost 20 years. The vegetation was typical of the foothill grasslands of northern Greece, which is dominated by the two bunchgrasses Andropogon ischaemum and Chrysopogon gryllus. Among the rather distinct bunches of these grasses, several other species, mainly annuals, were grown (Fig. 1). A list of the species encountered in the plots is given in Table 1.

Soils were shallow clayloams with small quantity of organic matter, typical of the brown Mediterranean soil type.

\section{Procedures}

Five quadrat sizes, $0.0625,0.125,0.250,0.500$, and $1 \mathrm{~m}^{2}$, and three quadrat shapes, square, rectangular, and circular were tested. For each size and shape combination five samples were taken from each of three blocks, $10 \times 10 \mathrm{~m}^{2}$, which were selected and located about $50 \mathrm{~m}$ apart. Table 2 shows the characteristics of quadrats used in the experiment. From here on, the five quadrat sizes are referred to as $1,2,3,4$, and 5 from the smallest to the largest size, respectively.

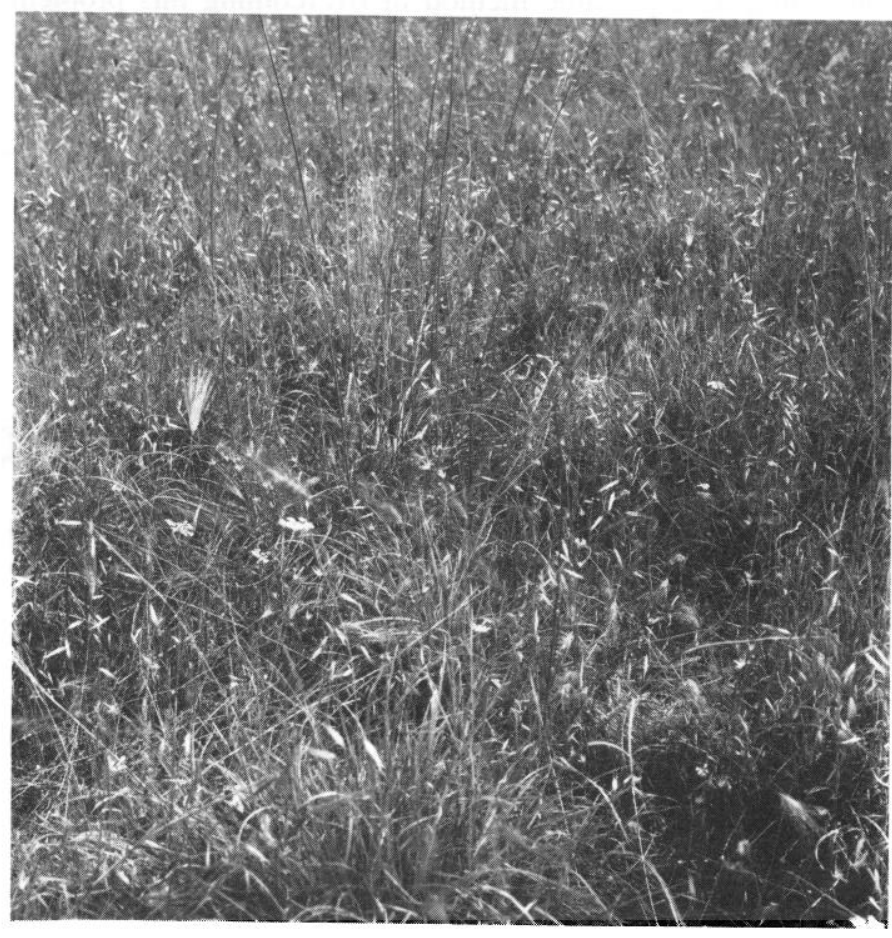

Fig. 1. Study site of the foothill grassland. Bunchgrass in the foreground is Andropogon ischaemum; tall grass in the background is Chrysopogon gryllus. 
Table 1. Species encountered in the plots with their frequencies (\%).

\begin{tabular}{|c|c|}
\hline Species $^{1}$ & Frequency $^{2}$ \\
\hline \multicolumn{2}{|l|}{ Grasses } \\
\hline \multicolumn{2}{|l|}{ Perennials } \\
\hline Andropogon ischaemum & 67 \\
\hline Chrysopogon gryllus & 33 \\
\hline Cynodon dactylon & 22 \\
\hline \multicolumn{2}{|l|}{ Annuals } \\
\hline Elymus caput-medusae & 100 \\
\hline Triticum villosum & 100 \\
\hline Avena sterilis & 89 \\
\hline Bromus commutatus & 56 \\
\hline Bromus arvensis & 22 \\
\hline Aegilops triuncialis & 11 \\
\hline \multicolumn{2}{|l|}{ Forbs } \\
\hline \multicolumn{2}{|l|}{ Short lived perennials } \\
\hline Carlina graeca & 78 \\
\hline Centaurea caerulescens & 56 \\
\hline Pastinaca sativa & 56 \\
\hline Eryngium creticum & 44 \\
\hline Lithospermum officinale & 33 \\
\hline \multicolumn{2}{|l|}{ Annuals } \\
\hline Trifolium angustifolium & 89 \\
\hline Asperula hirta & 78 \\
\hline Hymaenocarpus circinatus & 56 \\
\hline Nicella damascina & 44 \\
\hline Trifolium campestre & 44 \\
\hline Linum gallicum & 33 \\
\hline Onobrychis aequidentata & 33 \\
\hline Cerastium pilosum & 22 \\
\hline Gnaphalium germanicum & 22 \\
\hline Lamium amplexicaule & 22 \\
\hline Medicago tribuloides & 22 \\
\hline Valerianella coronata & 22 \\
\hline Other ( 12 species) & 11 or below \\
\hline
\end{tabular}

1 Nomenclature from Kavvadas, D. S. 1956. Econografimenon Botaniconphytologikon Lexikon. Vol. I-IX, Athinae.

2 Frequencies based upon nine quadrats of $1 \mathrm{~m}^{2}$ size.

Quadrats were made of iron rods of $8 \mathrm{~mm}$ diameter and they were placed randomly in each block.

Sampling was done in June 1974, by a group of five persons. Of those, three were assigned randomly to the various quadrats for clipping the vegetation with hand-operated shears, one recorded the clipping time, and the fifth person supervised the random placing of the quadrats in each block. The three-man clipping crew was dictated mainly by time considerations, since clipping herbage by hand is a slow process. This may have caused some variability in the data due to personal differences. However, these differences were kept to a minimum by selecting men with adequate experience in clipping and by frequent check of their work by the fifth person of the group. In addition, the different sizes and shapes of quadrats were interchanged among the three laborers in order to spread any possible variation uniformly over the treatments.

Total vegetation contained in each plot was clipped to ground level and put into paper bags. In the laboratory, the herbage yield was dried to $65^{\circ} \mathrm{C}$ in an oven prior to weighing. No attempt was made to separate green material from dead (litter).

Table 2. Area $\left(\mathrm{m}^{2}\right)$ and dimensions (length $\times$ width $\times$ diameter) $(\mathrm{m})$ of the quadrats used in the experiment.

\begin{tabular}{|c|c|c|c|c|}
\hline \multicolumn{2}{|c|}{ Size } & \multicolumn{3}{|c|}{ Shape } \\
\hline No. & Area & Square & Rectangular & Circular \\
\hline 1 & 0.0625 & $0.250 \times 0.250$ & $0.500 \times 0.125$ & 0.282 \\
\hline 2 & 0.1250 & $0.354 \times 0.354$ & $0.500 \times 0.250$ & 0.399 \\
\hline 3 & 0.2500 & $0.500 \times 0.500$ & $0.250 \times 1.000$ & 0.554 \\
\hline 4 & 0.5000 & $0.707 \times 0.707$ & $0.500 \times 1.000$ & 0.798 \\
\hline 5 & 1.0000 & $1.000 \times 1.000$ & $0.500 \times 2.000$ & 1.128 \\
\hline
\end{tabular}

Table 3. Herbage weight means with their standard errors (g/plot) for the various quadrat sizes and shapes.

\begin{tabular}{lrrr}
\hline & \multicolumn{3}{c}{ Shape } \\
\cline { 2 - 4 } Size & \multicolumn{1}{c}{ Square } & \multicolumn{1}{c}{ Rectangular } & \multicolumn{1}{c}{ Circular } \\
\hline 1 & $20.3 \pm 4.72$ & $25.0 \pm 3.15$ & $15.4 \pm 1.83$ \\
2 & $42.4 \pm 10.50$ & $50.6 \pm 8.48$ & $43.1 \pm 7.27$ \\
3 & $89.0 \pm 9.44$ & $94.6 \pm 14.29$ & $91.4 \pm 9.66$ \\
4 & $172.5 \pm 19.53$ & $145.7 \pm 13.96$ & $207.6 \pm 30.43$ \\
5 & $317.9 \pm 26.85$ & $292.2 \pm 22.34$ & $325.4 \pm 28.35$ \\
\hline
\end{tabular}

Recorded time included the time required to find and put each quadrat in a random place as well as to compile the data.

\section{Results and Discussion}

\section{Weight Means}

Herbage weight means are shown in Table 3. As expected, there was an almost linear increase in yields per quadrat from the smaller to the larger sizes. Also, rectangular quadrats gave higher yields than square or circular quadrats except for the two largest sizes, where yields of circular quadrats exceeded those of the other shapes.

Distribution of the weight data was pronouncedly skewed. Moreover, the weight variances of vegetation harvested from various quadrat sizes and shapes are not homogeneous because these quadrats sample different populations (Van Dyne et al. 1963).

To make the analysis of variance valid, herbage weight data were subjected to logarithmic transformation, which takes care of both the skewed distribution and the unequal variances (Greig-Smith 1964; Milner and Hughes 1968). Then, they were analyzed as a $5 \times 3$ factorial in a randomized complete block design with three blocks and five samples per block at a 0.05 level of significance (Hicks 1964).

Quadrat sizes were the only treatment which produced significantly different results. Further application of Duncan's test (Hicks 1964) showed that no two of the five quadrat sizes gave the same means.

The failure of the shapes to produce significant differences in herbage yields by this analysis may be attributed to the high variation of vegetation. Data not included in this paper show that Andropogon ischaemum, a leafy bunchgrass, contributed about $48 \%$ of the herbage yield although its frequency was relatively low (see Table 1). Chrysopogon gryllus, a bunchgrass also, contributed to about $15 \%$ of the herbage yield; while the remaining $37 \%$ was contributed by over 30 slender, mostly annual, species (Table 1). The sparseness of bunchgrass may be the main cause of yielding insignificant differences among shapes. Similar results were found by Hanson (1934) and Van Dyne et al. (1963).

\section{Weight Variation}

Comparison of the herbage yields was restricted to sizes, because shapes and size and shape interaction produced no significantly different results. The weight data were converted to a common basis, i.e. to quadrats of size $5\left(\mathrm{~g} / \mathrm{m}^{2}\right)$, and they were averaged over the shapes within each size class. Their means with their standard errors and variances are given in Table 4.

Since the number of quadrats (sample size) was the same for every quadrat size, it would have been expected that the variance decreased as the size of quadrat increased (Milner and Hughes 1968). This did happen to some extent because the largest size gave the lowest variance. However, the decrease 
Table 4. Herbage weight means with their standard errors $\left(g / \mathrm{m}^{2}\right)$, their variances, and the efficiencies, compared to the least variance, of the five quadrat sizes.

\begin{tabular}{cccc}
\hline \hline $\begin{array}{c}\text { Size of } \\
\text { quadrat }\end{array}$ & Means & Variance & $\begin{array}{c}\text { Statistical } \\
\text { efficiency }\end{array}$ \\
\hline 1 & $323.34 \pm 32.47$ & $47,452.78$ & 0.21 \\
2 & $363.20 \pm 40.16$ & $72,574.44$ & 0.14 \\
3 & $366.74 \pm 23.98$ & $25,905.92$ & 0.38 \\
4 & $350.44 \pm 26.37$ & $31,313.17$ & 0.32 \\
5 & $311.85 \pm 14.80$ & $9,851.85$ & 1.00 \\
\hline
\end{tabular}

was not quite clear in the other sizes (Table 4). This indicates the high variability of the range vegetation sampled.

Minimum variance indicates low variability. Therefore, the quadrat with the least variance can be considered to have provided an efficient estimate of the herbage weight compared to the estimates of the same population parameter by the other quadrat sizes. This concept of efficiency has been used by Pechanec and Stewart (1940) and Van Dyne et al. (1963) for statistical evaluation of quadrat size in herbage weight estimates.

The ratio of the least variance to the variance of each of the quadrat sizes can be considered as a measure of statistical efficiency (Table 4). The quadrat of the largest size (5) was statistically the most efficient quadrat; the size 2 quadrat was the least efficient.

Edge effect is an important source of error in quadrat work (Greig-Smith 1964; Kershaw 1973). Van Dyne et al. (1963) detected a positive bias in small plots which was attributed to their higher perimeter-to-area ratios compared to the larger plots. In this work, the ratios of weight per meter of perimeter per square meter of area were 76.9, 87.7, 89.3, 87.2, and 76.6 grams, respectively, for the sizes 1 to 5 . These ratios show that edge effect due to size possibly did not cause an error in herbage estimates.

\section{Clipping Time}

Clipping time varied from one minute for the smallest size to 23 minutes for the largest size. Analysis of variance of the time data, as a design similar to the one used for the weight data also gave significant results among sizes at the 0.05 level of significance. Shapes did not produce significant differences in clipping time as well as blocks and the interaction between size and shape. Use of Duncan's test gave significant differences among all size means.

Regression of herbage weight $(X)$ to clipping time $(Y)$ produced the following linear equation with $r=0.945$ :

$$
\hat{Y}=1.94+0.046 X
$$

Correlation coefficient was found significantly higher than zero with a $t$-test at the $\mathbf{0 . 0 5}$ level of significance (Snedecor and Cochran 1971). This means tht $89 \%$ of the variance in clipping time is accounted for by variation in herbage yield. The result agrees with what was found by Pechanec and Stewart (1940), who in addition indicated that clipping time accounted for $81 \%$ of the total time spent in collection and compilation of field data. Wiegert (1962) and Van Dyne et al. (1963) also found that clipping time increases with the size of quadrat. These results show the importance of selecting the optimum quadrat in clipping studies.

The average clipping time per quadrat size, all shapes combined, is shown in Table 5 along with the standard error of the means. Clipping time was increased by 50-55\% from the smaller size to the next larger. Exception was found for size 4, the clipping time of which was increased by $87 \%$ over the size 3 .
Table 5. Clipping time means with their standard errors (minutes) and the efficiencies, compared to the least time, of the five quadrat sizes.

\begin{tabular}{ccc}
\hline \hline Size of quadrat & \multicolumn{1}{c}{ Means } & Time efficiency \\
\hline 1 & $2.44 \pm 0.11$ & 1.00 \\
2 & $3.69 \pm 0.16$ & 0.66 \\
3 & $5.78 \pm 0.20$ & 0.42 \\
4 & $10.80 \pm 0.43$ & 0.22 \\
5 & $16.62 \pm 0.48$ & 0.15 \\
\hline
\end{tabular}

This suggests that the size 4 was large enough to cause increased fatigue over the smaller sizes.

The ratio of the minimum time to the time required by each quadrat size and shape can be considered as a measure of time efficiency. This ratio decreases as the quadrat size increases (Table 5).

\section{Optimum Quadrat}

An optimum quadrat size and shape is the one that provides an efficient estimate of herbage yield with the least cost, which is the sampling time. Assuming constant time (cost) for the sampling work, which is independent of the size of quadrat (walking between stations, weighing, etc.), Wiegert (1962) determined the optimum quadrat size by minimizing the product of variance and cost of each size relative to the variance and cost of the smallest size.

Based on Wiegert's notion and assuming that clipping time is the main cost factor in clipping work, the optimum quadrat in this study was determined by maximizing the product of statistical and time efficiency. Both efficiencies are the reciprocals of the relative measures used by Wiegert and they are shown in Tables 4 and 5. The data are graphed on Figure 2.

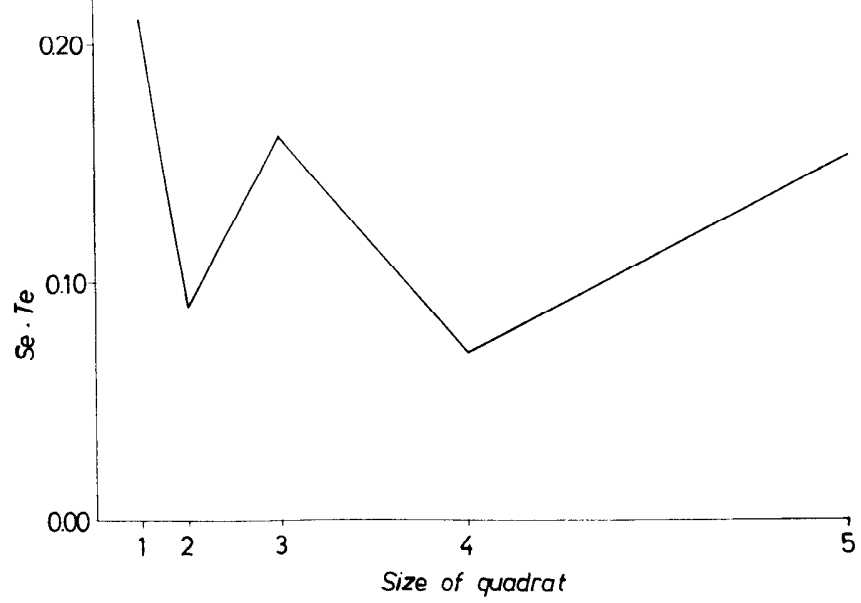

Fig. 2. Graph of statistical efficiency (Se) times time efficiency (Te) against the size of quadrat $\left(l=0.0625 \mathrm{~m}^{2}, 2=0.125 \mathrm{~m}^{2}, 3=0.250 \mathrm{~m}^{2}, 4=0.500 \mathrm{~m}^{2}\right.$, and $\left.5=1 \mathrm{~m}^{2}\right)$.

It turns out that, regardless of shape, a quadrat of size 1 $\left(0.0625 \mathrm{~m}^{2}\right)$ appears to be the optimum plot for sampling herbage weight in ungrazed foothill bunchgrass ranges of northern Greece.

Under grazing conditions, however, the optimum quadrat is expected to be larger. This is because grazing usually increases the variability in bunchgrass ranges (Van Dyne et al. 1963) which in turn would decrease the statistical efficiency of the small quadrats. Under these conditions, Figure 2 shows that a quadrat of size $3\left(0.250 \mathrm{~m}^{2}\right)$ would be possibly the optimum quadrat. A plot of about the same size, but of circular shape, is suggested for bunchgrass ranges, also, of the western U.S. by Van Dyne et al. (1963). 


\section{Literature Cited}

Brown, D. 1954. Methods of surveying and measuring vegetation. Commonwealth Bur. Pasture and Field Crops. Hurley Berks, England. Bull. 42. $233 \mathrm{p}$.

Greig-Smith, P. 1964. Quantitative plant ecology. 2nd ed. Butterworths Inc., England. $256 \mathrm{p}$.

Hanson, H. C. 1934. A comparison of methods of botanical analysis of the native prairie in Western North Dakota. J. Agr. Res. 49:815-842.

Hicks, C. R. 1964. Fundamental concepts in the design of experiments. Holt, Rinehart and Winston, New York. 293 p.

Joint Committee. 1962. Basic problems and techniques in range research. National Academy of Sciences, National Research Council. Pub. 890. $341 \mathrm{p}$.

Kershaw, K. A. 1973. Quantitative and dynamic plant ecology. 2nd ed. Edward Arnold, New York. 308 p.
Morris, M. J. 1967. An abstract bibliography of statistical methods in grassland research. U.S. Dep. Agr. Misc. Pub. 1030. 222 p.

Milner, C., and R. E. Hughes. 1968. Methods for the measurement of the primary production of grassland. IBP Handbook No. 6. Blackwell Sci. Publ., Oxford. $70 \mathrm{p}$.

Pechanec, J. F., and G. Stewart, 1940. Sagebrush-grass range sampling studies: size and structure of sampling unit. Amer. Soc. Agron. J. 32: 669-682

Snedecor, G. W., and W. G. Cochran. 1971. Statistical methods. 6th ed. lowa State Univ. Press. 593 p.

Van Dyne, G. M., W. G. Vogel, and H. G. Fisser. 1963. Influence of small plot size and shape on range herbage production estimates. Ecology 44: 746-759.

Wiegert, R. G. 1962. The selection of an optimum quadrat size for sampling the standing crop of grasses and forbs. Ecology 43:125-129. 